\title{
RECRIAÇÕES DE UM TEXTO LITERÁRIO, OU: DO RISO AO SUSSURRO
}

\author{
Marinyze das Graças Prates de Oliveira ${ }^{1}$
}

\begin{abstract}
Resumo: Promove-se, neste artigo, uma análise da coletânea Missa do galo: variações sobre o mesmo tema, na qual seis escritores fazem uma releitura do conto de Machado de Assis, adotando, em sua maioria, o ponto de vista de diferentes personagens. Procura-se explorar as similaridades entre tal operação e a transcriação de um texto literário para o cinema, bem como o fato de o ponto de vista das escravas negras, referidas no texto matricial, não ter sido adotado em nenhuma das novas versões do conto machadiano.

Palavras-Chave: Recriações; Ponto de vista; Subalternidade.
\end{abstract}

Abstract: This article proposes an analysis of the collection Missa do galo: variations on the same theme, in which six writers produce a rereading of the short story by Machado de Assis, most of them adopting a point of view of different characters. It also aims to explore the similarities between such operation and the transcreation of a literary text to the cinema, as well as the fact that the point of view of black slaves, referred to in the source text, was not adopted in any of the new versions of Machado's short story.

Key Words: Recreations; Point of view; Subalternity.

Na década de 1970, um grupo de seis escritores — Osman Lins, Julieta de Godoy Ladeira, Nélida Piñon, Antonio Callado, Autran Dourado e Lygia Fagundes Telles - decidiu realizar uma curiosa experiência: escrever novas versões do conto "Missa do galo", de Machado de Assis, instigados pelos dois primeiros, que tiveram tal ideia treze anos antes. $O$ resultado do empreendimento foi publicado com o título de Missa do galo: variações sobre o mesmo tema. Como o próprio Osman Lins lembra no prefácio da coletâ-

1 Professora do Instituto de Humanidades, Artes e Ciências Professor Mílton Santos (IHAC) da Universidade Federal da Bahia (UFBA) e do Programa Multidisciplinar de PósGraduação em Cultura e Sociedade do IHAC/UFBA; Doutora em Comunicação e Cultura Contemporâneas pela Faculdade de Comunicação da UFBA; atua nas áreas de Artes e Humanidades e coordena o Grupo de Pesquisa em Cultura e Subalternidades, vinculado ao Centro de Estudos Multidisciplinares em Cultura (CULT) e ao Pós-Cultura; vem se dedicando a estudos relativos ao diálogo entre cinema e literatura; é autora de $E$ a tela invade a página: laços entre literatura, cinema e João Gilberto Noll (2002) e Olhares roubados: cinema, literatura e nacionalidade (2004). Endereço eletrônico: mpratesoliveira@terra. com.br. 
nea, o exercício de leitura que empreenderam não corresponde a uma iniciativa inédita:

Havia exemplares semelhantes na pintura e na música: artistas retomando um tema já realizado por antecessores e desenvolvendo-o a seu modo. Também em literatura, são conhecidas, por exemplo, as inúmeras versões dos dramas gregos, que, inspirados em Homero, chegam até os nossos dias, espelhando, sem perda de identidade, a visão e o modo de operar de escritores muito distanciados entre si no espaço e no tempo ${ }^{2}$.

Ao enveredarem pelas brechas que o conto machadiano faculta, esses escritores oferecem uma demonstração das muitas possibilidades de se ler contemporaneamente um autor canônico do século XIX - ao ampliarem certas suspeitas, apenas insinuadas pelo autor do conto matricial, ou mesmo lançarem novos olhares sobre questões vistas de forma naturalizada naquele momento - e, adicionalmente, possibilitam reflexões sobre os processos de apropriação de uma obra alheia e os impasses e polêmicas que tal atitude comumente desperta.

\section{ENTRECRUZAMENTOS}

Embora Osman Lins tenha evocado, no prefácio da coletânea, a similaridade da operação de reescritura do conto machadiano com outras iniciativas que a precederam, apenas nas áreas de pintura, música e literatura, hoje é praticamente impossível não se levarem em consideração os meios audiovisuais - e sobretudo o cinema - quando tratamos dessa questão. As operações denominadas de remakes são uma constante tanto na história da produção cinematográfica quanto na da televisiva, por meio das quais, de tempos em tempos, retomam-se filmes e novelas, conferindo-lhes novas versões, não raro atualizadoras de aspectos que falam do momento histórico-social de sua produção. Muitos são os exemplos de obras literárias que receberam diferentes traduções para o cinema - as de Shakespeare talvez constituam os exemplares mais eloquentes - da mesma forma que têm sido abundantes os casos de obras originariamente concebidas para um dos meios serem recicladas - ou em certos casos, até mesmo ressignificadas - para um meio diferente, quando novelas transformam-se em filmes ou vice-versa.

2 LINS, Osman. In: CALLADO, Antonio et al. Missa do galo: variações sobre o mesmo tema, p. 7. 
Mas é sobretudo com o processo que tradicionalmente se convencionou denominar de adaptação literária que me interessa evocar a similaridade entre a operação de reescritura do conto "Missa do galo" com a que ocorre quando um romance, conto, poema, etc. é tomado como ponto de partida para a produção de uma obra cinematográfica. As polêmicas, nesse sentido, são tão antigas quanto a própria prática da adaptação, que vem ganhando diferentes denominações - tradução intersemiótica, (re)leitura, transcriação, trabalho de co-autoria - em um esforço para descontaminála da equivocada expectativa de "fidelidade" que tem ofuscado o olhar dos espectadores em geral, impedindo-os de fruir o aspecto mais fértil desse processo: o exercício de reinvenção que ele incontornavelmente pressupõe. Nesse sentido, as seis novas versões de "Missa do galo" são exemplares, na medida em que deixam patente que quem lê traduz, recria e, ao assim proceder, traz à cena marcas de um determinado momento histórico, bem como dos elementos que constituem a trajetória pessoal e social de cada artista ou realizador. Embora as novas versões guardem pontos de convergência com a matriz machadiana, é no eixo da dissimilitude que os seis autores inserem seu olhar, assumindo o resultado de seu investimento como "variações" e não como cópias.

Essas versões aqui examinadas ajudam-nos a entender - e até mesmo aceitar - que o texto artístico "se mantém sempre como reserva de surpresas e inovações para uma outra leitura, um outro tempo", guardando "a aptidão de poder ser lido/relido e escrito/reescrito em cada leitura" ${ }^{3}$. Deste modo, correspondem a exemplos potentes de uma operação críticocriativa e, tal como ocorre na adaptação de obras literárias para o cinema, estão sujeitas até mesmo a (auto)cobranças como as feitas por certos cineastas e críticos, impulsionados pelo receio de promover interferências em uma obra considerada inviolável. Como observa Robert Stam, a linguagem tradicional da crítica muitas vezes "tem sido extremamente discriminatória, disseminando a idéia de que o cinema vem prestando um desserviço à literatura [...]. Apesar da variedade de acusações, sua motriz parece sempre a mesma - o livro era melhor" ${ }^{4}$. Essa desconfiança transparece claramente nas palavras de Osman Lins, quando afirma que a novidade do empreendimento está no fato de ter simultaneamente acolhido a ideia "um certo número de ficcionistas, cada um deles aceitando o desafio de refazer, com

3 HOISEL, Evelina. A leitura do texto artístico, p. 7.

4 STAM. Robert. A literatura através do cinema: realismo, magia e a arte da adaptação, $\mathrm{p}$. 20. 
maior ou menor aproximação, o texto machadiano, que sabíamos insuperável. Este fator, aliás, se era próprio a fazer-nos perder o ânimo, também aliviava-nos: partiríamos para uma aposta antecipadamente perdida" ${ }^{5}$.

Dado o status ocupado por Machado de Assis no panteão das Letras brasileiras, compreende-se a reverência com que Osman Lins se reporta à obra do escritor oitocentista, chegando a quase penitenciar-se pelo ato de apropriar-se de uma obra sacralizada, imbuído de certo espírito de liberdade. Se, na década de 70, ir à tradição, apanhar certas obras e elementos artísticos, submetê-los a um processo de hibridização ou reciclagem era uma atitude que ainda comportava certos receios e solicitava justificativas, contemporaneamente é procedimento corrente - inclusive como forma de prestar uma homenagem a seus autores, segundo já admitia o próprio Osman Lins: "não nos importa muito se fomos ou não felizes nestes severos exercícios. O importante, para nós, é a homenagem que prestamos a Machado de Assis, e, através dele, à arte da ficção, cujos corredores e salas, segundo demonstra a breve coletânea, são inumeráveis" ${ }^{\prime}$.

A julgar por certos termos usados pelo escritor no prefácio da coletânea, não é difícil identificar uma atitude paradoxal em relação à experiência que coordenou. Se por um lado Osman Lins demonstra um espírito ousado, e até certo ponto transgressor, ao propor aos colegas rasurarem o conto machadiano, por outro atesta quanto ainda se encontra preso a uma visão no mínimo tradicional desse processo, através do uso de certos termos, já bastante marcados na tradição metafísica, para referir-se a tal operação: "publicamos aqui a peça machadiana, ou seja, o modelo - e as nossas seis versões sobre esse modelo"7; "Se a maior ou menor fidelidade ao modelo adveio de deliberação dos autores, não foram casuais ou arbitrários os pontos-de-vista adotados" ${ }^{8}$; "Autran Dourado, valendo-se do escrevente, revela-nos, para surpresa de todos, uma Conceição que, à primeira vista, parece contrariar a de Machado, mas na qual acabamos de descobrir, ampliados, certos textos do original" 9 .

\footnotetext{
LINS, Osman. In: CALLADO et al. Op. cit., p. 7. 


\section{UMA QUESTÃO DE PONTO DE VISTA}

Nessas novas versões de "Missa do galo", um aspecto me interessa de forma especial: a decisão dos escritores em adotar diferentes pontos de vista, de sorte a atribuírem a determinado personagem o privilégio do olhar - e, mais importante: da voz. Operação semelhante já foi por diversas vezes levada a cabo no cinema - para nos atermos apenas a esse meio valendo a pena lembrar o filme Rachomon (1950), de Akira Kurosawa, no qual um padre relata, em flash back, um julgamento do qual participou, na condição de testemunha do assassinato de uma mulher e do marido dela, um samurai. Durante a narração, vão sendo mostradas cenas do julgamento, nas quais vários personagens apresentam versões diferenciadas de como os fatos aconteceram e, por fim, o próprio morto é convocado mediunicamente a dar seu depoimento. Clint Eastwood, por sua vez, surpreendeu o mundo ao lançar simultaneamente em 2006 os filmes $A$ conquista da honra e Cartas de Iwo Jima, sobre um mesmo episódio da Segunda Guerra Mundial, visto respectivamente a partir da perspectiva dos soldados americanos e dos japoneses envolvidos no confronto. Por meio de tal artifício, ambos os diretores - coincidentemente um japonês e o outro americano - promovem uma relativização do conceito de verdade, reconhecendo no processo de interpretação as múltiplas possibilidades de acesso a um mesmo acontecimento.

Nas novas versões de "Missa do galo", os seis autores que participaram do projeto de leitura e reescrita do conto machadiano, impulsionados por diferentes motivações, acabam dando voz a quase todos os personagens do texto matricial. Uma ideia da maneira pela qual cada um deles se apropriou do conto pode ser conhecida pelo leitor da coletânea já no prefácio da publicação, por meio da síntese que Osman Lins oferece:

Assim é que Julieta de Godoy Ladeira explora a perspectiva da "boa Conceição"; Nélida Piñon se ocupa de Menezes, cuja intimidade devassa e para quem inventa uma linguagem tão interessante quanto ele; Antonio Callado aproxima-se de uma personagem apenas sugerida por Machado, a mãe de Conceição, levando-nos finalmente a entrever, por um mágico jogo de espeIhos, o perfil do grande escritor; Lygia Fagundes Telles, manipulando um estranho "eu" onisciente, procura invadir o mundo do conto, luta por modificálo e vê que tal tentativa é vã. Autran Dourado, valendo-se do escrevente, revela-nos, para surpresa de todos, uma Conceição que, à primeira vista, pare- 
ce contrariar a de Machado, mas na qual acabamos de descobrir, ampliados, certos traços, tênues no original $^{10}$.

Nesse depoimento, Osman Lins omitiu a informação de que em sua própria leitura escolheu, como aliás o tinha feito o próprio Machado de Assis, o ponto de vista do adolescente - aspecto que não parece nada casual - a quem denominou de Nogueira. Além do mais, ao trazer à cena personagens do conto que tiveram seu ponto de vista contemplado pelos autores das novas versões, Lins põe em evidência o fato de que apenas duas delas continuaram condenadas ao silêncio: as escravas negras, uma vez que mesmo a $D$. Inácia e ao escrevente, também referidos de forma passageira pelo narrador do texto-fonte, é dado expressarem-se, respectivamente nas versões de Antonio Callado e Autran Dourado.

Explica ainda Osman Lins no prefácio que, na reescritura do conto "Missa do galo", a fim de "evitar monotonia ou repetições, sugeri - sugeri, não estabeleci - perspectivas diversas" ${ }^{11}$. A ambiguidade de que se reveste tal declaração permite pelo menos duas interpretações: por um lado, Osman Lins assume total responsabilidade pela escolha dos pontos-de-vista a serem adotados pelos companheiros de aventura literária. Contudo, a intercalação da ressalva - "sugeri, não estabeleci" - que vem logo em seguida, dissolve a certeza anterior. Como se pode, enfim, compreender a interferência de Osman Lins nesse processo? Enquanto uma simples recomendação de que não se deveria utilizar um mesmo personagem como narrador de diferentes versões do conto, ou, mais explicitamente, como uma sugestão/determinação de qual personagem deveria desempenhar essa função na versão a ser elaborada por cada um dos colegas de ofício? Se, no primeiro caso, a responsabilidade da escolha recairia integralmente sobre cada um dos escritores que abraçaram a tarefa, no segundo não se pode negar que, através da concordância com a sugestão de Osman Lins, torna-se impossível eximi-los de cumplicidade na eleição desses narradores. Logo, a preterição das escravas como sujeitos falantes pode ser atribuída, de uma forma ou de outra, aos seis escritores que participaram dessa atividade lúdica.

10 Idem, ibidem, p. 8.

11 Idem, Loc. cit.

74 Número temático: literatura e cinema. A Cor das Letras - UEFS, n. 11, 2010 


\section{DO CONTEXTO AO TEXTO}

O fato é que, tanto a coletânea de versões de "Missa do galo" quanto certas transposições para os meios audiovisuais de uma mesma obra literária, realizadas em contexto histórico-social bastante distanciado do momento de produção das obras matriciais, constituem excelentes espaços para a observação da permanência de posturas tradicionais na construção das próprias imagens identitárias que passam a veicular. Desta forma, promover uma leitura dessas "leituras" do conto machadiano, auxiliada pelo instrumental teórico-crítico que a contemporaneidade tem nos facultado evidenciador do peso que as construções culturais exercem sobre as relações de poder na sociedade ocidental - pressupõe a inserção em um jogo interpretativo que envolve três diferentes temporalidades e remete a contextos sócio-históricos peculiares: o final do século XIX, quando é produzido o conto por Machado de Assis; a década de setenta, momento em que se efetivam as releituras há muito sonhadas por Osman Lins e Julieta de Godoy Ladeira, e a contemporaneidade, na qual se situa a análise que desejo aqui empreender.

Nessas seis versões do conto machadiano, e consequentemente na adoção de pontos de vista diferentes em cada uma delas, merece destaque o papel que é reservado às duas escravas referidas no texto de partida. As imagens de negros e afro-descendentes construídas pela literatura no século XIX, notadamente a partir do projeto romântico de instituição da nacionalidade, refletem claramente os dilemas de nossos escritores frente a uma questão incômoda. Se José de Alencar, em uma operação radical, decidiu bani-los de $O$ Guarani, os demais escritores oitocentistas, impedidos pelas evidências de alijar os negros da cena doméstica ou urbana, passaram a representá-los como étnica e socialmente diferenciados, naturalizando, portanto, sua condição de serviçais dos que se julgavam brancos, europeus ou abastados. A tais aspectos se somaria, no final do século, uma mentalidade plasmada pelas teorias raciológicas importadas do pensamento europeu, que definiam as posições na hierarquia étnico-racial do ocidente. Nesse contexto, as imagens dos personagens negros e afro-descendentes construídas por nossos escritores passaram a oscilar entre a invisibilidade, a função decorativa e o mutismo, como em A Moreninha, de Joaquim Manuel de Macedo; ou entre tais características e a índole traiçoeira e violenta, segundo se pode constatar em $O$ cortiço, de Aluísio Azevedo. 
O próprio Machado de Assis, intelectual mestiço e neto de escravos, não se manteve imune às acusações, por certa fração da crítica, de não ter se envolvido diretamente na luta abolicionista - na visão de Alfredo Bosi, ele foi um "discreto simpatizante" ${ }^{12}$ dessa causa - e de haver construído imagens negativas de personagens negros, muito embora tenha, em certos momentos de sua obra, questionado de forma contundente a ordem social vigente e a insensibilidade diante da escravidão, conforme se dá nos sempre lembrados contos "O caso da vara" e "Pai contra mãe". Em certos momentos da obra machadiana, por trás da aparente indiferença do autor, pode-se ler, ao contrário do que por muito tempo se supôs, justamente a referência ao espírito escravocrata da burguesia fluminense, merecendo ser evocado o conto "O espelho", no qual os perfis dos serviçais negros transitam da naturalização de sua condição de escravos ao seu rebaixamento a uma posição de criaturas pérfidas. Como evidenciaram investimentos críticos mais recentes - a exemplo dos empreendidos por Raimundo Faoro em A pirâmide e o trapézio e Robert Schwarz em Ao vencedor as batatas - a complexidade da obra machadiana há muito pedia uma maior atenção a certos aspectos sobre os quais os estudiosos do autor ainda não haviam se debruçado com a necessária atenção. Cedendo ao apelo, Eduardo de Assis Duarte realizou um trabalho de capinagem e reuniu no livro Machado de Assis afro-descendente, poemas, contos, crônicas e trechos de romances, de sorte a propiciar aos leitores a oportunidade de reavaliarem os juízos disseminados a respeito do posicionamento do escritor em relação à prática da escravidão no Brasil oitocentista.

No conto "Missa do galo", Machado de Assis faz apenas duas breves referências - e em um mesmo trecho curto - às escravas negras, momentos em que o narrador age como uma câmera cinematográfica que, em um plano geral, acaba capturando quase que acidentalmente certos objetos em meio ao todo, sem no entanto conferir-Ihes qualquer destaque ou expressividade:

A família era pequena, o escrivão, a mulher, a sogra e duas escravas. Costumes velhos. Às dez horas da noite toda a gente estava nos quartos; às dez e meia a casa dormia. Nunca tinha ido ao teatro, e mais de uma vez, ouvindo dizer ao Menezes que ia ao teatro, pedi-Ihe que me levasse consigo. Nessas

12 BOSI, Alfredo. Machado de Assis, p. 21.

76 Número temático: literatura e cinema. A Cor das Letras - UEFS, n. 11, 2010 
ocasiões, a sogra fazia uma careta, e as escravas riam à socapa; ele não respondia, vestia-se, saía e só tornava na manhã seguinte ${ }^{13}$.

Embora o realista Machado de Assis inclua as escravas negras no grupo familiar, confere-lhes apenas o direito a ouvir as conversas dos moradores da casa e tirar conclusões, mas nunca de expressá-las, em uma prática similar à que vigora até hoje no seio das residências brasileiras, nas quais sempre se alimenta a expectativa de que as empregadas - que em sua quase totalidade continuam sendo negras - "saibam o seu lugar" na ordem social e doméstica. Os artifícios de camuflagem da opressão também não variaram muito do século XIX para o momento presente: consideradas, muitas vezes, como "quase pessoas da família", as empregadas domésticas permanecem sem direito a voz e relegadas aos quartos do fundo, em uma perpétua reedição das estratégias hierarquizadoras vigentes sobretudo em sociedades que tiveram um passado escravista como a nossa.

Todavia, mais que a postura de Machado de Assis, que escreveu no século XIX e sob a pressão de um contexto social no qual a prática do racismo se encontrava abrigada sob a chancela de uma (pseudo-)ciência, interessa-me analisar aqui a dos seis escritores que, quase um século após a publicação do conto pelo autor oitocentista, deliberaram promover diferentes traduções de "Missa do galo". Diferentemente de Machado de Assis, esses autores encontravam-se ancorados em um momento de eclosão de importantes movimentos de resistência dos negros à opressão, iniciado sobretudo nos Estados Unidos e espraiado em seguida por diversos países, inclusive o Brasil.

\section{DO RISO AO SUSSURRO}

Dos seis autores da coletânea, quatro se referem às escravas. Nélida Piñon, incorporando uma sutileza tipicamente machadiana, sugere, através do nome atribuído à escrava, sua condição de sofredora: "Conceição forçava-me a desistir. Até que, não mais suportando, levantou-se a pretexto de chamar Suplicia, urgia que a mucama fosse ao boticário curá-la da enxaque$\mathrm{ca}^{14}$. Na operação atualizadora de Julieta Ladeira, a escrava transforma-se em criada, ora mostrada como uma criatura destituída de qualquer traço de

13 ASSIS, Machado de. In: CALLADO et al. Op. cit., p. 13. Grifos meus.

14 PIGÑON, Nélida. In: CALLADO et al. Op. cit, p. 35.

Cláudio Cledson Novaes, Fernanda Aguiar C. Martins, Roberto H. Seidel (Org.) 
subjetividade - "Refeições servidas cedo, a criada saindo antes das oito, Menezes e o jornal, minha mãe tricotando junto ao rádio" ${ }^{15}$ - ora como alguém a quem cabe apenas obedecer a ordens: "E mandei a criada tirar a colcha de sua cama, por causa do calor"16. Antonio Callado, ao enfatizar a negligência das escravas, paradoxalmente concede-lhes a possibilidade da desobediência: "Agora tinha estalado a outra porta [...] era o ruído daquela maçaneta de vidro vermelho onde boiavam margaridinhas brancas, presa à sua placa por pregos frouxos e cujo conserto, por mais que fosse recomendado às escravas, não se providenciava nunca" ${ }^{17}$; Lygia Fagundes Telles, a seu turno, permite às escravas uma ascensão do riso ao sussurro, mas cujos comentários não ultrapassam as paredes de seu quarto de dormir: "Mas tem alguém dormindo? A começar pelas mucamas lá no fundo da casa: já estão de camisola e conversam baixinho, a mais nova trançando a carapinha em trancinhas duras, rindo do patrão que devia estar todo contente, montado na concubina, ouviu essa palavra mais de uma vez, acabou aprendendo, concubina" ${ }^{18}$.

Não obstante tais referências correspondam a uma repetição em diferença do gesto do autor oitocentista, elas não chegam a subverter o padrão representacional do texto-matriz, nem contêm uma potência capaz de resgatar as serviçais da posição marginal a que foram relegadas. Deste modo, o exercício de reescritura do conto "Missa do galo" apresenta seis variações não apenas sobre o mesmo tema, mas especialmente sobre uma mesma postura: a de silenciamento da voz das personagens negras. Como enfatiza Foucault,

em uma sociedade como a nossa, conhecemos, é certo, procedimentos de exclusão. O mais evidente, o mais familiar também é a interdição. Sabe-se bem que não se tem o direito de dizer tudo, que não se pode falar de tudo em qualquer circunstância, que qualquer um, enfim, não pode falar de qualquer coisa $^{19}$.

Apoiados na liberdade crítico-criativa que preside contemporaneamente os exercícios de "adaptação", foi possível a Nélida Piñon desenhar os contornos de um outro Menezes, movida pelo propósito de escancarar o

\footnotetext{
15 LADEIRA, Julieta de Godoy. In: CALLADO et al. Op. cit., p. 56.

16 Idem, ibidem, p. 60.

17 CALLADO, Antonio. In: Op. cit., p. 69.

18 TELLES, Lygia Fagundes. In: CALLADO et al. Op. cit, p. 102.

19 FOUCAULT, Michel. A ordem do discurso, p. 9.

78 Número temático: literatura e cinema. A Cor das Letras - UEFS, n. 11, 2010
} 
comportamento sórdido e machista do personagem; a Osman Lins substituir o livro Os três mosqueteiros, com que o estudante ocupava seu tempo, por $O$ vermelho e o negro, e ver na senhora de Rênal a própria Conceição; a Julieta Ladeira construir um novo perfil da esposa de Menezes, de modo a reverter o modelo de mulher e esposa arquitetado pela mentalidade patriarcal, que a enclausurava entre quatro paredes; a Antonio Callado transportar Capitu do Dom Casmurro para sua própria versão de "Missa do galo"; a Autran Dourado apropriar-se de uma brevíssima e maliciosa referência do velho Machado ao fato de Conceição, após a morte de Menezes, ter-se casado com o escrivão juramentado do marido, e transformá-lo no Joaquim Fontainha Távora, protagonista de sua história; e, por fim, a Lygia Fagundes Telles agir como uma roteirista, em sua tentativa de lembrar-se de cada detalhe mencionado no texto de partida. Logo, é pertinente inquirir: por que então nenhum deles deliberou dar voz às escravas que, na casa de Menezes, a tudo viam e ouviam e contemporaneamente teriam muito a dizer sobre a situação das mulheres negras e pobres que habitam as periferias dos grandes centro urbanos; a respeito da maneira como continuam sendo representadas nos filmes e novelas; ou ainda sobre a tripla discriminação de que ainda são vítimas na sociedade brasileira?

\section{ENTRE FALAR E (NÃO) SER OUVIDO}

Em seu contundente ensaio intitulado "Pode o subalterno falar?" publicado inicialmente em 1986, Gayatri Spivak desenvolve reflexões que podem nos auxiliar na interpretação dessa problemática. A autora entende os subalternos como "as camadas mais baixas da sociedade constituídas pelos modos específicos de exclusão dos mercados, da representação política e legal, e da possibilidade de se tornarem membros plenos no estrato social dominante ${ }^{\prime 20}$. Ancorada na desconstrução derridariana, ela promove uma forte crítica aos intelectuais ocidentais, notadamente a Deleuze e Foucault que, a partir de visões expostas em "Os intelectuais e o poder", promovem segundo Spivak, "uma valorização não questionada do oprimido como sujeito" ${ }^{21}$ e, concomitantemente, se mostram acríticos "quanto ao papel histórico do intelectual" que, na opinião da autora, não pode falar pelo outro,

20 SPIVAK, Gayatri. Apud ALMEIDA, Sandra Regina Goulart. In: Pode o subalterno falar?, p. 12.

21 SPIVAK, Gayatri. Op. cit., p. 29.

Cláudio Cledson Novaes, Fernanda Aguiar C. Martins, Roberto H. Seidel (Org.) 
pois, ao fazê-lo, reproduz as estruturas de poder e colabora para a manutenção da opressão. Ao intelectual caberia um papel diferente: criar espaços para que o subalterno possa ser ouvido, já que essa impossibilidade bloqueia inclusive sua capacidade de auto-representação.

Como importante contribuição crítica ao próprio Grupo de Estudos Subalternos, ao qual se encontra vinculada, Spivak promove uma dupla crítica: à orientação teórica do projeto, que opera com a ideia do subalterno "como construtor de seu próprio destino", e à "ausência de estudos que incorporassem perspectivas de gênero" ${ }^{22}$. Enfatiza a autora que, no "contexto do itinerário obliterado do sujeito subalterno, o caminho da diferença sexual é duplamente obliterado", uma vez que "a construção ideológica de gênero mantém a dominação masculina". A seu ver, se "o sujeito subalterno não tem história e não pode falar, o sujeito subalterno feminino está ainda mais profundamente na obscuridade ${ }^{23}$. Sua conclusão é de que, como o subalterno não pode falar, na medida em que lhe é impossível estabelecer relações dialógicas, "a mulher subalterna continuará tão muda como sempre esteve" ${ }^{24}$.

Caso aceitemos os argumentos apresentados por Spivak, poderemos entender tanto a postura de Machado de Assis, quanto a dos seis autores das novas versões de "Missa do galo", como uma recusa em assumirem o que a autora indiana viria a classificar, na década de 1980, como uma atitude do "intelectual ocidental benevolente" ${ }^{25}$, que incorre em uma "utopia perigosa" ${ }^{26}$. Enfim, o que essas "variações sobre o mesmo tema" atestam é nada menos que a permanência de uma impossibilidade: a de a voz dos subalternos ser ouvida. Se no conto machadiano, escrito no século XIX, às escravas negras era permitido no máximo "rir à socapa", nas recriações da década de 1970 elas vão do direito ao sussurro - como ocorre na versão de Lygia Fagundes Telles - ao absoluto silêncio que Ihes reservam Nélida Piñon e Julieta de Godoy Ladeira. O fato de essas personagens sequer serem citadas nas demais versões subtrai-Ihes a condição de sujeitos e potencializa sua invisibilidade social, práticas naturalizadas em culturas como a

\footnotetext{
22 CHAKRABARTY, Dipesh. Una pequeña historia de los estudios subalternos, p. 20.

23 SPIVAK, Gayatri. Op. cit., p. 66-67.

24 Idem, ibidem, p. 86.

25 Idem, ibidem, p. 79.

26 Idem, ibidem, p. 73.

80 Número temático: literatura e cinema. A Cor das Letras - UEFS, n. 11, 2010
} 
brasileira que, por meio de artifícios ardilosos, atuam permanentemente na produção e manutenção da subalternidade.

\section{REFERÊNCIAS}

ALENCAR, José de. O Guarani. São Paulo: Ática, 1973.

AZEVEDO, Aluísio. O cortiço. São Paulo: Ática, 1998.

BOSI, Alfredo. Machado de Assis. São Paulo: Publifolha, 2002.

CALLADO, Antonio et al. Missa do galo: variações sobre um mesmo tema. São Paulo: Summus, 1977.

CHAKRABARTY, Dipesh. Uma pequeña historia de los Estudios Subalternos. Anales de desclassificación. Universidade de Chicago, s.d.

DUARTE, Eduardo de Assis. Machado de Assis afro-descendente: escritos de caramujo antologia. Belo Horizonte: Crisálida, 2007.

EASTWOOD, Clint. A conquista da honra, 2006.

EASTWOOD, Clint. Cartas de Iwo Jima, 2006.

FAORO, Raymundo. Machado de Assis: a pirâmide e o trapézio. São Paulo: Globo, 2001.

FOUCAULT, Michel. A ordem do discurso. Trad. Laura Fraga de Almeida Sampaio. São Paulo: Loyola, 1996.

FOUCAULT, Michel. Os intelectuais e o poder. In: Id. Microfísica do poder. Conversa entre Michel Foucault e Gilles Deleuze. Trad. Roberto Machado. Rio de Janeiro: Graal, 1999.

HOISEL, Evelina. A leitura do texto artístico. Salvador: Ed. UFBA, s.d.

KUROSAWA, Akira. Rachomon, 1950.

MACEDO, Joaquim Manuel de. A Moreninha. São Paulo: Ática, 1998.

OLIVEIRA, Marinyze Prates de. Olhares roubados: cinema, literatura e nacionalidade. Salvador: FAPESB/Quarteto: 2004.

SCHWARZ, Roberto. Ao vencedor as batatas. São Paulo: Duas Cidades/34, 2000.

SPIVAK, Gayatri. Pode o subalterno falar? Trad. Sandra Regina Goulart Almeida et al. Belo Horizonte: Ed. UFMG, 2010.

STAM, Robert. A literatura através do cinema. Trad. Marie-Anne Kremer e Gláucia Renate Gonçalves. Belo Horizonte: Ed. UFMG, 2008. 
